\title{
Clinical Profile of Haemophilia In Children in A Tertiary Care Hospital
}

\author{
KARIM MA ${ }^{1}$, SIDDIQUE R ${ }^{2}$, JAMAL $\mathrm{CY}^{3}$, ISLAM A ${ }^{4}$
}

\begin{abstract}
:
Introduction : Haemophilias are the most common inherited coagulation disorders transmitted by $X$ - linked recessive fashion affecting the males and females are the carriers of the disease. Haemophilias are distributed worldwide and have heterogeneous presentation depending upon its severity starting from neonatal period. Knowledge of spectrum of presentation of haemophilia helps in early diagnosis and planning of management.
\end{abstract}

Objectives : To observe the clinical presentation of haemophilia in children

Methodology: This observational study was carried out in the Department of Pediatric Hematology and Oncology, Bangabandhu Sheikh Mujib Medical University for a period of one year from $1^{\text {st }}$ July 2007 to $30^{\text {th }}$ June 2008. Clinical profile of 50 diagnosed cases of haemophilia $<15$ years of age was analyzed.

Result: All the 50 cases of haemophilia were male. Mean age of the patients was $6.62 \pm 3.87$ years with an age range of 6 months to 14 years. Forty (80\%) cases were haemophilia A and 10 (20\%) cases were Haemophilia B. Only $40 \%$ cases had family history of bleeding. Among the Haemophilia A, 52.5\% cases had mild, $47.5 \%$ cases had moderate disease and among the Haemophilia B, 40\% cases had mild, 50\% cases had moderate and $10 \%$ cases had severe disease. Heamarthrosis of knee joint was the major presentation followed by oral cavity bleeding, bleeding following tooth extraction and circumcision. Sixty two percent cases had initial bleeding episode before 1 year of age and by 5 years of age $94 \%$ of cases had produced symptoms. No patient had history of bleeding during neonatal period. Bruises and hematoma were the most common initial manifestation followed by joint bleeding, cut injury of lips and chin, scalp and facial hematoma.

Conclusion: Bruises, hematoma and joint bleeding either spontaneous or after trauma were the main feature at initial presentation of haemophilia in children, so presence of these features in an otherwise normal child should be considered for evaluation of haemophilia. More vigilance is to be needed for detection of haemophilia in newborn.

Key wards: Haemophilia, Hemarthrosis, bleeding disorder

Introduction:

Haemophilias are the most common inherited coagulation disorders. The inheritance is $X$ linked recessive, affecting the males and females are the

1. Associate Professor, Dept of Pediatric Hematology and Oncology, Bangabandhu Sheikh Mujib Medical University, Dhaka

2. Medical Officer, Dept of Pediatric Hematology and Oncology, Bangabandhu Sheikh Mujib Medical University, Dhaka

3. Professor, Dept of Pediatric Hematology and Oncology, Bangabandhu Sheikh Mujib Medical University, Dhaka

4. Professor \& Chairman,Dept of Pediatric Hematology and Oncology, Bangabandhu Sheikh Mujib Medical University, Dhaka Correspondence: Dr. Md. Anwarul Karim, Email: anwarulkarim 94@yahoo.com carriers of the disease ${ }^{1,2,3}$. Haemophilia $A$ and Haemophilia B are the commonest form of Haemophilia encountered and they result from defect in Factor VIII and Factor IX gene respectively. The defective gene leads to decreased or absent production of FVIII or FIX resulting in excessive and prolonged bleeding ${ }^{2}$. Approximately $30 \%$ of patients have no family history; their disorder is presumably caused by new mutation ${ }^{4}$. Haemophilia is distributed worldwide ${ }^{5}$. Incidence of haemophilia $A$ and $B$ is $1: 10000$ and 1:60000 males respectively ${ }^{6,7}$. Haemophilia has been recognized a clinical entity since Biblical times as evidenced by 
the writings of a Rabi in a Babylonian Talmud, "If she circumcised her first son and he died and a second son also died she must not circumcised her third child" 8,9. In 1803, a Philadelphia doctor John Conrad Otto published a treatise about the 'Hemorrhagic disposition' which he recognized as inherited and occurring in male ${ }^{10}$. In 1828, it was first identified as haemophilia - the term first used by University of Zurich student Friederick Hopf ${ }^{11}$.

Frequency and severity of bleeding is generally related to blood level of clotting factors ${ }^{12}$. Depending on the clotting factor concentration the disease is divided into mild ( $>5 \%$ factor level), moderate ( $1-5 \%$ factor level), and severe $(<1 \% \text { factor level })^{3}$. Severe and moderate haemophiliac might present at birth with prolonged bleeding from umbilical stump or intracranial hemorrhage ${ }^{2,13}$. Beyond neonatal period these patients usually present around 11 months of age when the child is learning to walk and has frequent fall or bumps into the furniture ${ }^{2}$. Sometimes, prolonged bleeding from tongue bite, mouth laceration or soft tissue bruising brings to notice of these severe or moderately severe haemophiliacs ${ }^{13}$. Serious Intracranial hemorrhage $(\mathrm{ICH})$ from trivial trauma endanger life of these severe haemophiliacs ${ }^{14}$. Older children and adolescent haemophiliacs present with joint swelling and persistent or repeated joint haemorrhages lead to synovial inflammation leading to hypertrophy and a vicious cycle of re bleeding into joint space induce developing 'target joints' 2,5 . Muscle hemorrhage may threatened life or limbs owing to compression of blood vessels or nerve 2,5 . Mild haemophilia might present lately during childhood and bleeding is not spontaneous rather secondary to trauma or invasive procedure and recurrent haemarthrosis and consequent arthropathy occur rarely 15,16 .

In the past, male with haemophilia were likely to die in young age ${ }^{17}$. Before clotting factor concentrate were available most people with severe Haemophilia developed crippling musculoskeletal deformities and would have died due to haemorrhage ${ }^{18}$. With advances in diagnosis, and especially with development of safe and effective treatment, affected individuals can now look forward to a normal life expectancy.

The mainstay of management of haemophilia is the prophylaxis with replacement of clotting factors in moderate and especially severe haemophiliacs aiming to prevention of bleeding episodes with their pathological consequences like intracranial hemorrhages, arthropathy and muscular contractures $^{19}$. So it is of crucial importance that correct diagnosis is established as soon as possible after birth so that appropriate therapy may be instituted without delay especially in severe haemophiliacs ${ }^{13}$.

Clotting factor concentrate prophylaxis aims to preserve joint function by converting severe haemophilia to clinically milder form of disease resulting in significant reduction of arthropathy and to prevent life threatening bleeding ${ }^{19,20}$.

Information regarding children with haemophilia in our settings is scarce. In one study of clinico-pathological aspect of haemophilia was reported in which only $44 \%$ of the study cases were children $<15$ years and the study was conducted at adult setting with inclusion of cases with joint swelling and did not reflect the situation of haemophilia in children exactly prevailing. So this study was designed to observe the clinical presentation of haemophilia in children in a tertiary care hospital where patients are being referred from different corners of the country which will provide glimpse of presentation of pediatric Haemophilia in our country.

\section{Methodology}

This cross sectional study was carried out in the department of Paediatric Haematology and Oncology, Bangabandhu Sheikh Mujib Medical University for a period of one year from $1^{\text {st }}$ July 2007 to $30^{\text {th }}$ June 2008. A total of fifty cases were studied. Known haemophiliacs or suspected cases with bleeding disorders those afterwards were diagnosed as haemophilia either admitted into inpatient or attending at out patient department of Paediatric Haematology and Oncology were included in the study. For new cases of haemophilia who had received coagulation factors, fresh frozen plasma or cryoprecipitate within 24 hours were excluded from the study. After getting informed consent from the parents / guardians of the patients, detailed history regarding presenting symptoms including symptoms at first presentation and family history of the same disease were taken. Bleeding history of first presentation was taken from parents and from documents of the treating physicians. Thorough physical examinations to evaluate symptoms were also done. For new cases relevant investigations like complete blood count, prothrombin time (PT), activated partial thromboplastin time (APTT), factor VIII and IX assay were done. 
Reports of the CBC, PT, APTT and factors assay were collected from the patients who were diagnosed previously. Diagnosis of haemophilia was made on the basis of prolonged APTT, and lower level of coagulation factors with normal PT and hemogram. The finding of the history, clinical examination and investigation were recorded in the semi structured questionnaires. Haemophilia $A$ and $B$ was defined as deficiency of Factor VIII and IX with $<30 \%$ of normal activity respectively. Mild, moderate and severe haemophilia were defined as factor level of $>5-30 \%$, $1-5 \%$ and $<1 \%$ of normal activity respectively.

\section{Results:}

Among 50 cases of haemophilia studied, all patients in this series were male. Mean age of the patients was $6.62 \pm 3.87$ years with an age range of 6 months to 14 years. Seventy six percent of the patients were in age group $<11$ years and $24 \%$ patients were above age of 11 years (table-I). Haemophilia A was found in $40(80 \%)$ cases and $10(20 \%)$ cases were haemophilia B (figure-1). Only $40 \%$ cases had positive family history out of them $30 \%$ cases had affected brothers, $8 \%$ cases had affected maternal uncle and $2 \%$ had maternal cousins (table-II).

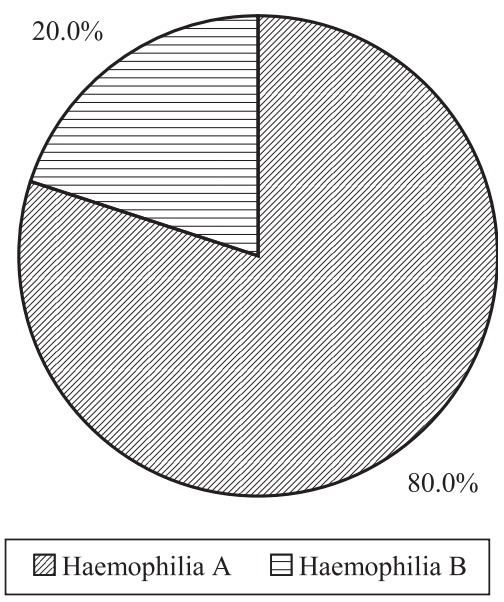

Fig.-1: Distribution of patients by types of haemophilia

Table-I

Age distribution of patient with haemophilia

\begin{tabular}{lccc}
\hline Age group & \multicolumn{2}{c}{ Types } & Total \\
& Haemophilia A Haemophilia B & number (\%) \\
\hline Up to 5 & $16(32 \%)$ & $6(12 \%)$ & $22(44 \%)$ \\
$6-10$ & $12(24 \%)$ & $4(8 \%)$ & $16(32 \%)$ \\
$11-15$ & $12(24 \%)$ & $0(.0)$ & $12(24 \%)$ \\
\hline Total & $40(80 \%)$ & $10(20 \%)$ & $50(100 \%)$ \\
\hline
\end{tabular}

Table-II

Family history of haemophilia

\begin{tabular}{lcc}
\hline & Frequency & Percent \\
\hline Positive family history & 20 & 40.0 \\
Maternal uncle & 04 & 08 \\
Other sibs & 15 & 30 \\
Maternal cousin & 01 & 02 \\
Negative family history & 30 & 60.0 \\
\hline Total & 50 & 100.0 \\
\hline
\end{tabular}

Distribution of haemophiliacs depending on severity among the different groups is shown in table-3. Among haemophiliaA, $52.5 \%$ were mild and $47.5 \%$ were moderate haemophilia on the other hand $40 \%$ of haemophilia B presented with mild disease, $50 \%$ with moderate form of the disease and $10 \%$ with severe disease.

Table-III

Distribution of haemophilia according to severity

\begin{tabular}{lcc}
\hline Severity & \multicolumn{2}{c}{ Types } \\
& Haemophilia A & Haemophilia B \\
\hline Mild & $21(52.5)$ & $4(40.0)$ \\
Moderate & $19(47.5)$ & $5(50.0)$ \\
Severe & $0(00)$ & $1(10.0)$ \\
\hline Total & $40(100.0)$ & $10(100.0)$ \\
\hline
\end{tabular}

Most common problem with which the patients presented in this series was hemarthrosis (82\%). Gum bleeding (38\%) was the second common problem of the haemophiliacs at presentation followed by prolonged bleeding after tooth extraction in $28 \%$ cases. Four percent cases had prolonged bleeding following circumcision. Hematuria, melena, epistaxis and intracranial hemorrhage $(\mathrm{ICH})$ were the presentation each in $2 \%$ cases (table-IV).

Table-IV

Presentation of haemophilia

\begin{tabular}{lcc}
\hline Features & Frequency & Percentage \\
\hline Joint swelling & 41 & 82 \\
Oral and gum bleeding & 19 & 38 \\
Bleeding following tooth & 14 & 28 \\
extraction & & \\
Bruises and echymoses & 4 & 8 \\
Scalp hematoma & 4 & 8 \\
Circumcisional bleeding & 2 & 4 \\
Hematuria & 1 & 2 \\
Melena & 1 & 2 \\
ICH & 1 & 2 \\
\hline
\end{tabular}

* Multiple responses 
In this study, knee joint swelling was present in 58\% cases of Haemophilia A and $10 \%$ cases of Haemophilia B. Ankle joint involvement was found in $36 \%$ cases of Haemophilia A and $8 \%$ cases of Haemophilia B, Elbow joint swelling was found in 12\% of Haemophilia A and $2 \%$ cases of Haemophilia B. Shoulder joint and Hip joint involvement were found in $8 \%$ and $6 \%$ cases of Haemophilia A only (table-V).

Table-V

Frequency of involvement of joints

\begin{tabular}{|c|c|c|c|}
\hline \multirow{3}{*}{ Involved Joints } & \multicolumn{2}{|c|}{ Types } & \multirow{3}{*}{$\begin{array}{l}\text { Total } \\
(\%)\end{array}$} \\
\hline & \multicolumn{2}{|c|}{ Haemophilia Haemophilia } & \\
\hline & $\mathrm{A}(\%)$ & B (\%) & \\
\hline Knee & $29(58)$ & $5(10)$ & $34(68)$ \\
\hline Ankle & $18(36)$ & $4(8)$ & $22(44)$ \\
\hline Elbow & $6(12)$ & $1(2)$ & $7(14)$ \\
\hline Shoulder & $4(8)$ & $0(.0)$ & $4(8)$ \\
\hline Hip & $3(6)$ & $0(.0)$ & $3(6)$ \\
\hline Others & $3(6)$ & $0(.0)$ & $3(6)$ \\
\hline
\end{tabular}

Out of $82 \%$ cases of joint swelling, $54 \%$ cases showed limitation of movement of the affected joints, $46 \%$ in Haemophilia A and $8 \%$ cases in Haemophilia B and $12 \%$ patients had compartmental syndrome in which $10 \%$ cases in Haemophilia $A$ and $2 \%$ cases in Haemophilia B. ICH was present in 1patient with Haemophilia B which was due to trauma (table-VI).

TableV

Complication of haemophilia

\begin{tabular}{lccc}
\hline Parameters & \multicolumn{2}{c}{ Types } & Total \\
\cline { 2 - 3 } & $\mathrm{A}(\%)$ & $\mathrm{B}(\%)$ & \\
\hline $\begin{array}{l}\text { Limitation of } \\
\text { movement of } \\
\text { joints }\end{array}$ & $23(46)$ & $4(8)$ & $27(54)$ \\
$\begin{array}{l}\text { Compartmental } \\
\text { syndrome }\end{array}$ & $5(10)$ & $1(2)$ & $6(12)$ \\
ICH & $0(0)$ & $1(2)$ & $1(2)$ \\
\hline
\end{tabular}

Most of the patients (62\%) in this series had their first bleeding symptoms before first birth day and $94 \%$ cases showed bleeding manifestation before 5 years of age. Only $6 \%$ cases had presented after 5 years of age (table-VII).
Table-VII

Age distribution at initial presentation

\begin{tabular}{lcc}
\hline Age range & Frequency & Percent \\
\hline$<1$ year & 31 & 62.0 \\
1-5 years & 16 & 32.0 \\
$>5$ years & 3 & 6.0 \\
Total & 50 & 100.0 \\
\hline
\end{tabular}

Initial presentation of the children with haemophilia is shown in table -VIII. Most common initial presentation of the haemophiliac was bruises and ecchymosis in $40 \%$ of cases that occurred spontaneously or following trauma. Hemarthrosis was the presentation in $20 \%$ cases and spontaneous gum bleening in $4 \%$ cases and the rest $36 \%$ cases presented with prolonged bleeding following trauma as cut injury of lips and chin $(16 \%)$, scalp and facial hematoma (16\%), gum bleeding ( $8 \%)$, tongue bite $(4 \%)$, prolonged bleeding following circumcision (2\%).

Table-VIII

Initial presentation of haemophilia

\begin{tabular}{lcc}
\hline Features & Frequency & Percentage \\
\hline Bruises and Echymoses & 20 & $40 \%$ \\
Hemarthrosis & 10 & $20 \%$ \\
Cut injury to lips and chin & 8 & $16 \%$ \\
Scalp and facial hematoma & 8 & $16 \%$ \\
Tongue bite & 2 & $4 \%$ \\
Gum bleeding & 2 & $4 \%$ \\
Circumcisional bleeding & 1 & $2 \%$ \\
\hline
\end{tabular}

Discussion:

Haemophilia is a common hereditary bleeding disorder with variable clinical presentation depending upon the severity of the problem. To observe the clinical profile of the Bangladeshi children with Haemophilia 50 cases were studied. Family history pattern in the present series is similar to the earlier study on Bangladeshi population by Rahman and Uddin et al. ${ }^{21,22}$. Study on Korean Haemophiliacs by Kim et al. and on Indian haemophiliacs by Kar and Pontis - Lele showed comparable result ${ }^{23,24}$. On the other hand, Mac Lean et al. in their study in Netherlands showed high positive family history in $71 \%$ cases, however $31 \%$ of these mothers did not know about their carrier status during the birth of their children ${ }^{25}$. So carrier detection might explore more family to be carrier of Haemophilia. Brothers, maternal cousins and maternal uncle were 
found to be haemophiliacs in Korean study ${ }^{23}$. Findings of the present study are similar to their report.

In the present series, $80 \%$ of the Haemophiliacs had Haemophilia A and $20 \%$ had Haemophilia B. Similar finding was reported by Uddin et al. in their study on Bangladeshi people and Kar \& Pontis-Lele on Indian Haemophiliacs ${ }^{22,24}$. Higher percentage of Haemophilia A has been reported by Kim et al. in their study on Korean people and Ikkala on Finish Haemophiliacs ${ }^{23,26}$. On the other hand Hazwinkel et al. showed lower percentage of HaemophiliaA in South African Haemophiliacs ${ }^{27}$.

In the present study, $52.5 \%$ of Haemophilia A and $40 \%$ of Haemophilia B had mild disease, $47.5 \%$ of Haemophilia A and $50 \%$ of Haemophilia B had moderate disease, and only $10 \%$ of Haemophilia B had severe disease. Similar result was reported by Rahman and Uddin et al. in two different studies on Bangladeshi people with 45\% mild Haemophilia, 42.5 $\%$ moderate Haemophilia and $12.5 \%$ severe Haemophilia ${ }^{21,22}$. Kar and Pontis- Lele also showed similar findings with higher percentage of mild Haemophilia in their study on Indian Haemophiliacs ${ }^{24}$. Aznar et al. in their study on Spanish Haemophiliacs and Nilsson in his study on Swedish haemophiliacs also showed higher percentage of mild cases ${ }^{30,33}$. On the other hand Kim et al. in their study on Korean population showed more cases of severe Haemophilia $(55.7 \%)^{23}$. Higher percentage of severe haemophilia also has been reported by Ikkala in Finland, Hazewinke et al. in South Africa and Windyga et al. in Poland 26,27,29.

Haemarthrosis was the leading cause of medical attention in haemophiliacs observed in this study in $82 \%$ cases followed by gum bleeding in 38\% cases and excessive bleeding after tooth extraction in $28 \%$ cases. Recurrent joint swelling as predominant clinical presentation was also observed by Uddin et al. in earlier study on Bangladeshi Haemophiliacs ${ }^{22}$. In Korean nation wide study, joint symptoms was the presenting sign in $81 \%$ cases followed by easy bruising, prolonged bleeding after trauma and soft tissue haematoma ${ }^{23}$. But in Spanish Haemophiliacs, arthropathy was reported in less number of cases $13.7 \%$ in Haemophilia A and $4.1 \%$ cases in Haemophilia $B^{30}$. South African study showed subcutaneous hematoma was the leading symptoms for diagnosis in $51 \%$ cases of severe haemophilia, they reported only $5 \%$ cases with joint or muscle bleeding in severely affected cases, $21 \%$ cases in moderately affected and $9 \%$ cases in mild Haemophilia ${ }^{27}$.
Knee joint was the most commonly affected joint in $68 \%$ cases followed by ankle joint swelling in $44 \%$ cases, elbow joint swelling in $14 \%$ cases, shoulder joint swelling was present in $8 \%$ cases, hip and other joint swellings were observed in $6 \%$ cases. Korean study also reported knee joint swelling as predominant joint swelling in $84 \%$ cases followed by ankle joint and elbow joint swelling in $21 \%$ and $22 \%$ cases respectively ${ }^{23}$. In their study hip joint involvement was higher in $12.3 \%$ cases but wrist and shoulder joint involvement was low in $2.1 \%$ and $0.8 \%$ cases respectively ${ }^{23}$. Higher frequency of ankle joint involvement was also reported by Molho et al. in Haemophiliacs in France ${ }^{34}$. However Aznar et al. showed ankle joint was mostly affected followed by knee and elbow joint in Spanish haemophiliacs ${ }^{30}$. Similar frequency of joint involvement was also reported by Plug et al. in haemophiliacs in Netherlands ${ }^{35}$.

Initial presentation of the children with haemophilia was evaluated by analyzing the available physician's documents and parent's recall. Bruises and echymoses were the most common initial presentation in $40 \%$ of cases as per description of the parents. Joint swelling was present in $20 \%$ cases and gum bleeding was reported in $4 \%$ cases. Thirty six percent cases had bleeding following some form of trauma such as tongue bite, gum bleeding and injury to lip or chin, tooth extraction, circumcision and scalp injury. James et al. studied initial presentation of Haemophiliac children by analyzing 65 male patients presented for evaluation of presumed coagulopathy where $35.7 \%$ of diagnosis of Haemophilia were made after positive family history, $32.1 \%$ after iatrogenic bleeding like circumcision, venepuncure and heal prick and the rest $32.1 \%$ cases after spontaneous bleeding like bruising hematoma, cepalohematoma, gastrointestinal bleeding and $\mathrm{ICH}^{36}$. Jamil et al. studied initial presentation of severe Haemophiliacs and showed circumcision being the most common cause of iatrogenic bleeding and bruising hematoma as major cause of spontaneous bleeding. ${ }^{37}$. Higher percentage of patients compared to the present series with $\mathrm{ICH}$ was also reported by Jamil et al. ${ }^{37}$.

Majority (64\%) of the haemophiliacs in this series had initial bleeding episode before 1 year of age and by 5 years of age $94 \%$ cases showed evidence of active bleeding but none of the cases had bleeding during neonatal period. This might reflect under diagnosis of 
haemophilia in our setting in neonatal period. James at el showed $64.2 \%$ cases with severe haemophilia presented with bleeding episode before 1 month of age $^{36}$. Jamil et al. also showed $64.3 \%$ cases with severe haemophilia were detected at birth ${ }^{37}$. latrogenic bleeding following circumcision, venepuncture, heal prick were the common presentation in the newborn period. $\mathrm{ICH}$ with high potential for mortality and morbidity was observed in about $3-4 \%$ cases of severe haemophilia ${ }^{38,39}$. So, more vigilance is needed for the diagnostic evaluation for the children with bleeding episode during neonatal period in search of haemophilia.

Different studies showed that increasing number of patients are being diagnosed on the basis of family history during neonatal period because of organized haemophilia care ${ }^{36,37,38}$. In our setting dedicated haemophilia care yet to develop to provide quality care to the Haemophiliacs.

\section{Conclusion:}

Although haemarthrosis was the leading cause of presenting feature of the haemophilia in children in the present setting, bruises and hematoma either spontaneous or traumatic were the main features at very onset of presentation of these children. So presence of these features in an otherwise normal child should be considered for evaluation of haemophilia. No patient had any history of bleeding in the neonatal period. This warrants more vigilance for detection of haemophilia in newborn.

\section{References:}

1. Scott JP, Montgomery RR. Hemorrhagic and thrombotic disorder. In: Kliegman RM, Behrman RE, Jenson BF (eds.). Nelson's Text Book of Pediatrics, $18^{\text {th }}$ edition Saunder, Philadelphia. 2010; Pp 2061-88.

2. Lusher JM. Haemophilia A and B. In: Lilleyman JS, Hann IM, Balanchette VS (eds). Pediatric Hematology, $2^{\text {nd }}$ edition, Churchill Livigstone, London 1999; Pp 585-600.

3. Lanzkowsky P. Hemostatic disorders. In: manual of Pediatric Hematology and Oncology, $5^{\text {th }}$ edition, Elsevier, UK 2011; Pp 378-418.

4. Kulkerni R, Lusher J. Perinatal management of newborn with haemophilia. $\mathrm{Br} \mathrm{J}$ Hematol 2001; 112: $264-74$

5. Bolton-Maggs PHB and Pasi KJ. Haemophilia A and $B$. The Lancet 2003; 361: 1801-09.
6. Price VE, Hawen SA, Chan AK. A practical approach to Haemophilia in children. Peditr Child Health 2007; 12: 381-83.

7. Shaha MM, Ullah SMJ, Mondol DK, Bakar MA, Bhuiya JH, Haemophilia: An Update. J Bangladesh Coll Phys Surg 2007; 25: 29-37.

8. Mckusicks VA, Rapaport SI. History of classical Haemophilia in a New England family. Arch Inten Med 1998; 110: 144-148.

9. History of haemophilia Retrieved June 12, 2012. From www.Frankley net/history of Haemophilia.

10. Ingram GIC. The history of haemophilia. J Clin Path 1976; 29: 469-469.

11. Chalmers AE. Haemophilia and the new born. Blood reviews 2004: 18: 85-92.

12. Biggs R and Macfarlane RG. haemophilia and Related Conditions: A survey of 187 cases. Brit J Haematol 1958; 4: 1-27.

13. Ljung R, Petrini P, Nilsson IM. Diagnostic symptoms of severe and moderate Haemophilia A and B: A survey of 140 cases. Acta Paediatr Scand 1990; 79: 196-200.

14. Kulkarni R and Lushar JM. Intracranial and extracranial hemorrhage in newborn with haemophilia: A Review of literature. J. Pediatr Haematol and Oncol 1999 ; 21: 289-95.

15. Hoyer LW. Haemophilia A. N Eng J Med 1994; 330: 38-47.

16. Tagliaferri A. Di Perna C, Riccardi F, Pattacini C, Rivolta GF, Franchini M. Natural history of mild haemophilia: a 30 year single centre experience. Haemophilia 2012; 18: 166-74.

17. Jones P. Haemophilia: a global challenge. Haemophilia; 1: 11-13.

18. Balak DMW, Gouw SC, Plug I, MauserBunschoten EP, Vriends AHJT, Van- DiemenHoman AHJT et al. Prenatal Diagnosis for haemophilia: A Nationwide survey among female carrier in the Netherlands. Haemophilia 2012; 18: 584-92.

19. Ljung R. Prophylactic therapy in haemophilia. Blood Reviews 2009; 23: 267-274.

20. Pollmann $\mathrm{H}$, Richter $\mathrm{H}$, Jurgen $\mathrm{H}$. When are children diagnosed as having severe Haemophilia and when do they start to bleed? A 10 year 
single centre PUP study. Eur J Pediatr 1999; 158(sup-3); S166-S170.

21. Rahman M. Clinico-pathologic study on haemorrhagic disorder. (Dissertation) Dhaka, Bangladesh College of Physicians and Surgeons, 1998.

22. Uddin MM, Rahman MJ, Rahman MM, Sultana SA, Shah MS. Clinico-Pathological Study on haemophilia: An Analysis of 50 Cases. J Bangladesh Coll Phys Surg, 2006; 24: 50-53.

23. Kim KY, Yang $\mathrm{CH}$, Cho $\mathrm{MJ}$, Lee $\mathrm{M}$. Comprehensive clinical and statistical analysis of haemophilia in Korea 1988. J Korean Med Sc; 3: 107-14.

24. Kar A and Pontis-Lele M. Descriptive epidemiology of haemophilia in Maharastra, India. Haemophilia 2001; 7: 561-567.

25. MacLean PE, Fijnvandraat K, Beijlevelt M, Peters $M$. The impact of unaware carrier ship on the clinical presentation of haemophuilia. Haemophilia 2004; 10: 560-64.

26. Ikkla E. Haemophilia -A study of its laboratory clinical genetic and social aspects based on known haemophiliacs in Finland. Scand J Clin and Lab Invest. 1980; 46: 1-144.

27. Hazewinkel MH, Hoogerwarf JJ, Hesseling PB, Hertley $P$, MacLean PE, Peters $M$ et al. Haemophilia patients aged 0-18 years in Western Cape. SAMJ. 2003; 13: 793-96.

28. Aznar JA, Abad - Franch L, Cortina VR, Marco $P$. The inherited bleeding disorder group from Spanish society of thrombosis and haemostasis. The national registry of Haemophilia A and B in Spain: results from a census of patients. Haemophilia 2009; 15: 1327-53.

29. Windyga J, Lopaciuk S, Stefanska E, Juszynski A, Wozniak D , Strzelecki O, Szczepanik AB.
Haemophilia in Poland. Haemophilia 2006; 12: 52-57.

30. Aznar JA, Lucia F, Abad- Frach L, JimenezYuste V, Perez R, Baflle J et al. Haemophilia in Spain. Haemophilia 2009; 15: 665-75.

31. Colvin BT. Haemophilia in UK: Past, Present, future: Haemophilia 1995; 1 (suppl 2); s4-5.

32. Registry of inherited coagulopathies in Brazil: First report. Haemophilia 2009; 15: 142-49.

33. Nilsson IM. Management of Haemophilia in Sweeden. Thromb-Haemost 1976; 35:510-521.

34. Molho P, Rolland N, Lebrun T, Dirat G, Courpied $J P$, Cronghs $T$ et al.Epidemiological survey of the orthopaedic status of severe haemophilia A and B patients in France. Haemophilia 2000; 6 : 23-32.

35. Plug I, vanderBorn JG, Peters M, MauserBursChoten EP, De Goede-Bolder A, Heijnen L et al. Thirty years of haemophilia treatment in the Netherlands, 1972-2001. Blood; 104: 34943500 .

36. Conway JH, Hilggatner MW, Initial Presentation of Pediatric Haemophiliacs. Arch Ped Adoles 1994; 148: 589-594.

37. Jamil I, Bayoumy M, Iran D, Adler B. Pediatric severe Haemophilia: Initial presentation, characteristics and complications. The internet journal of Hematology 2004; 1 : ISSN 1540-2649.

38. Ljung $\mathrm{R}$, Chambost $\mathrm{H}$ Stain AM Dimichele D. Haemophilia in the first year of life. Haemophilia 2008; 14 (suppl 3): s188-195.

39. Baehner RL and Strauss HS. Haemophilia in $1^{\text {st }}$ year in life. N Eng J Med 1966; 275: 524-528.

40. Dyson $\mathrm{H}$, Neonatal haemophilia -a guide to recognition and management. Haemophilia 2006;2 156-159. 